\title{
Structural and magnetic properties of $\mathrm{BaCo}_{2-x} \mathrm{Ni}_{x} \mathrm{Fe}_{16} \mathrm{O}_{27}$ hexagonal ferrite prepared by a simple heat treatment method
}

\author{
Chetna C. Chauhan ${ }^{1 a}$, Rajshree B. Jotania ${ }^{2 b}$ \\ ${ }^{1}$ Institute of Technology, Nirma University, Ahmedabad - 382 481, Gujarat, India \\ ${ }^{2}$ Department of Physics, University School of Sciences, Gujarat University, Ahmedabad - 380 009, Gujarat, India \\ ${ }^{a}$ chetna.chauhan@nirmauni.ac.in, ${ }^{b}$ rbjotania@gmail.com
}

PACS 61.05.cp, 75.50.Vs, 75.60.Ej, 81.05.-t, 81.07.Wx

DOI 10.17586/2220-8054-2016-7-4-595-598

\begin{abstract}
A series of nickel-doped barium cobalt hexagonal ferrite samples with chemical composition $\mathrm{BaCo}_{2-}{ }_{x} \mathrm{Ni}_{x} \mathrm{Fe}_{16} \mathrm{O}_{27}(x=0.4,0.8,1.2,1.6$ and 2.0) were prepared using a simple heat treatment method. The dried precursor was calcined at $650{ }^{\circ} \mathrm{C}$ for 3 hours in a muffle furnace and slowly cooled to room temperature in order to obtain nickel-doped barium cobalt hexagonal ferrite powder. The prepared hexagonal ferrite powder samples were characterized using X-ray diffraction (XRD) and Vibrating Sample Magnetometer (VSM) techniques in order to study the effect of nickel substitution on structural and magnetic properties of barium cobalt hexagonal ferrites. The XRD analysis confirms the formation of mixed phases of W, M and spinel (S). The prepared powders exhibited single and multi-domain structures.
\end{abstract}

Keywords: Nickel doped barium cobalt hexagonal ferrites, heat treatment method, structural and magnetic measurements.

Received: 28 January 2016

Revised: 25 May 2016

\section{Introduction}

Barium hexaferrites possess magnetoplumbite crystal structure and have been extensively studied because of their large intrinsic uniaxial anisotropy and high Curie temperature, which make them widely used as permanent magnets, microwave devices and high density magnetic recording media, microwave absorbers, components and shielding [1-3]. Hexagonal ferrites are used in various components at high frequency range due to their high magnetic anisotropy, high Curie temperature, mechanical hardness, very low electrical conductivity, low dielectric loss, excellent chemical stability and corrosion resistance; their magnetic properties arise from the interactions between metallic ions occupying particular positions relative to the oxygen ions in its hexagonal crystalline structure $[4,5]$. It is well known that structural and magnetic properties of barium hexaferrites strongly depend upon preparation method, substitution of Fe with other kind of ions and amount [6]. W-type hexagonal ferrites possess seven different sites $\left(4 \mathrm{f}_{I V}, 2 \mathrm{~d}, 12 \mathrm{k}, 6 \mathrm{~g}, 4 \mathrm{f}, 4 \mathrm{f}_{V I}\right.$ and $\left.4 \mathrm{e}\right)$ in hexagonal crystal lattice, out of them five are magnetic sites. Iron ions are distributed among these sites of hexagonal crystal lattice [7]. Substitution of divalent or trivalent ions among various sublattices of hexagonal lattice can be used to improve intrinsic magnetic properties of barium hexaferrites [7]. During last decade various efforts have been made to improve structural and magnetic properties of barium hexaferrites by divalent and trivalent substitutions [8-10].

In the present investigation, a simple heat tratment method is adopted to prepare nickel substituted barium cobalt hexaferrite powder. The main objective of present investigation is to study the effect of nickel substitution on structural and magnetic properties of $\mathrm{BaCo}_{2-x} \mathrm{Ni}_{x} \mathrm{Fe}_{16} \mathrm{O}_{27}(x=0.4,0.8,1.2,1.6$ and 2.0) hexaferrite powder prepared by a simple heat treatment method and calcined at $650{ }^{\circ} \mathrm{C}$ for 3 hours.

\section{Experimental}

A series of $\mathrm{BaCo}_{2-x} \mathrm{Ni}_{x} \mathrm{Fe}_{16} \mathrm{O}_{27}(x=0.4,0.8,1.2,1.6$ and 2.0) hexaferrite is synthesized using high purity metal nitrate reagent as precursors, polyvinyl pyrrolidone (PVP) $\left[\left(\mathrm{C}_{6} \mathrm{H}_{9} \mathrm{NO}\right)_{n}\right]$ as a capping agent to reduce the agglomeration of the magnetic particles and deionized water was used as the solvent. The aqueous PVP solution is prepared by dissolving $3 \mathrm{~g}$ of polymer in $100 \mathrm{ml}$ of deionized water and kept at $70{ }^{\circ} \mathrm{C}$. Next, $1.6 \mathrm{mmol}$ of iron nitrate $\left[\left(\mathrm{Fe}\left(\mathrm{NO}_{3}\right)_{2}\right)\right], 0.1 \mathrm{mmol}$ of barium nitrate $\left[\mathrm{Ba}\left(\mathrm{No}_{3}\right)_{2}\right], 0.2$ mmole of cobalt nitrate $\left[\left(\mathrm{CoN}_{2} \mathrm{O}_{6} \cdot 6 \mathrm{H}_{2} \mathrm{O}\right)\right]$ and 0.4 mmole nickel nitrate $\left[\mathrm{Ni}\left(\mathrm{NO}_{3}\right)_{2}\right]$ solution was added into PVP solution and then kept on a magnetic stirrer for 2 hours. The mixed solution was heated at $80{ }^{\circ} \mathrm{C}$ and the resulting orange thick slurry was recovered. The obtained slurry was heated at $650{ }^{\circ} \mathrm{C}$ for 3 hours to obtain nickel-doped barium cobalt hexaferrite powder, which was crushed in to fine powder using a mortar and pastel. The same procedure is repeated for $x=0.8,1.2,1.6$ and 2.0 samples. 


\section{Results and discussion}

\subsection{Crystal Structure}

A Bruker D.Z. Phaser diffractometer (PW 1830) revealed X-ray powder diffraction (XRD) pattern when using $\mathrm{Cu}-\mathrm{K} \alpha$ radiation $(\lambda=1.5405 \AA)$ with a step scan of $0.02{ }^{\circ} \mathrm{C} / \mathrm{min}$ to determine the crystal structure of ferrite powder. Fig. 1 shows the XRD patterns of $\mathrm{BaCo}_{2-x} \mathrm{Ni}_{x} \mathrm{Fe}_{16} \mathrm{O}_{27}(x=0.4,0.8,1.2,1.6,2.0)$ powder samples. The XRD analysis reveals presence of W-ferrites (JCPDS No. 78-0135), M-ferrites (JCPDS No. 43-0002) and S-ferrites $\mathrm{Fe}_{3} \mathrm{O}_{4}$ (JCPDS file - PDF \# 790417) in final product; both W and M possess hexagonal while S possesses spinel crystal structure. No traces of $\alpha-\mathrm{Fe}_{2} \mathrm{O}_{3}$ was noted, as was observed in Ba-Ca hexaferrite [11,12] prepared by the sol gel technique. It is reported [13] that the unit cell of $\mathrm{W}$ phase is closely related to the M-phase, the only difference is that the successive R blocks are inter placed by two S-blocks instead of one as in the M-phase. It has also been reported by other researcher [14] that W-type hexagonal ferrite is chemically unstable and some of W-phase decomposed with the M-phase.

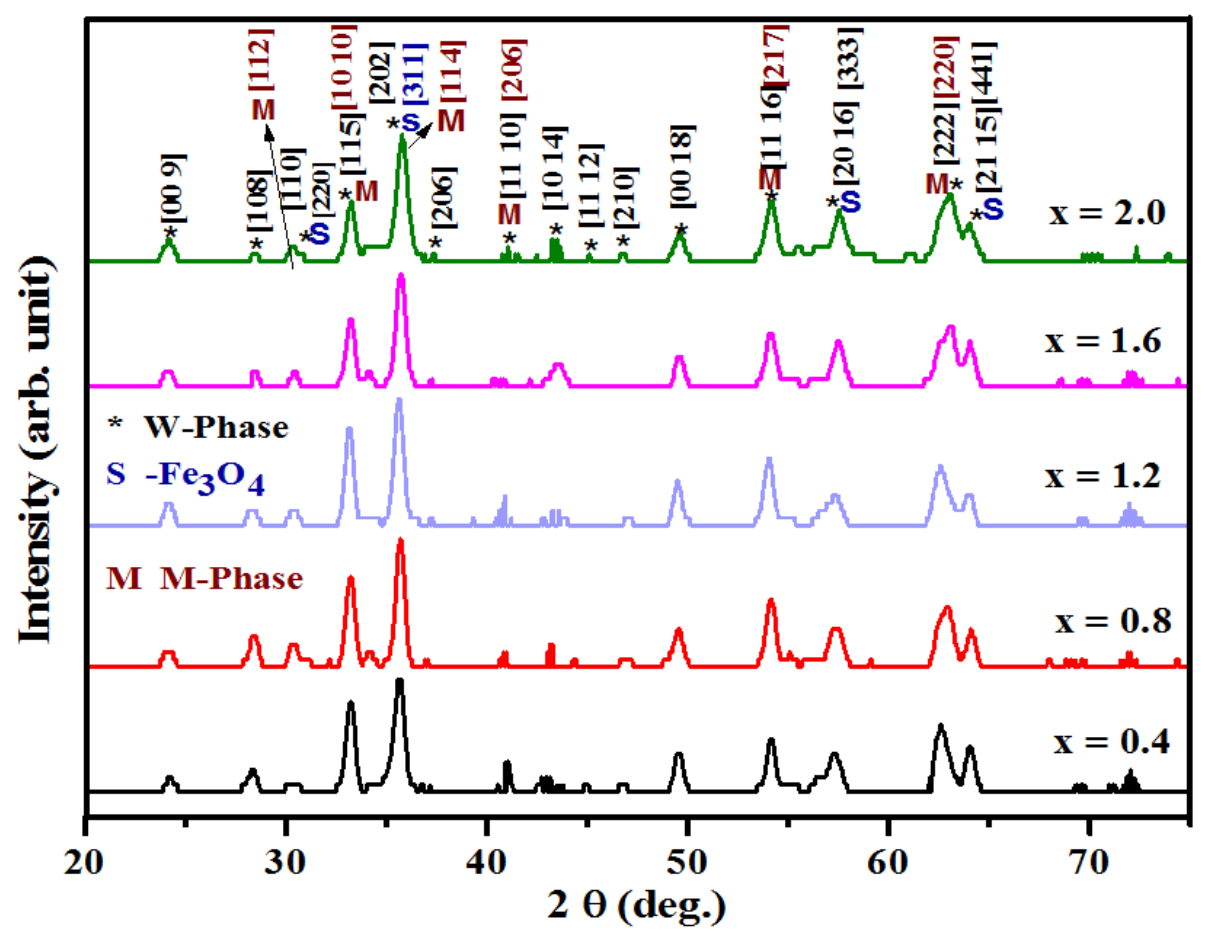

FIG. 1. X-ray diffraction patterns of $\mathrm{BaCo}_{2-x} \mathrm{Ni}_{x} \mathrm{Fe}_{16} \mathrm{O}_{27}(x=0.4,0.8,1.2,1.6,2.0)$ powder samples prepared using a simple heat treatment method and calcinated at $650{ }^{\circ} \mathrm{C}$ for 3 hours

The variation of lattice parameters $a, c$ their ratio $(c / a)$ and cell volume with the substitution of nickel are listed in Table 1. It is clear from Table 1 that value of $(c / a)$ for all the samples remains constant. This behavior can be explained on the basis of ionic radii of the substituted ions. The ionic radius of $\mathrm{Co}^{+2}$ is $0.65 \AA$, which is nearly of the same order of that of $\mathrm{Ni}^{+2}$ ions $(0.69 \AA)$. This confirms that $\mathrm{Ni}^{+2}$ ions replaces $\mathrm{Co}^{+2}$ ions in the structure without disturbing the hexagonal symmetry. The average crystalline size $\left(D_{x r d}\right)$ of the prepared $\mathrm{BaCo}_{2-x} \mathrm{Ni}_{x} \mathrm{Fe}_{16} \mathrm{O}_{27}(x=0.4,0.8,1.2,1.6,2.0)$ powder samples is calculated from the strongest Bragg peak [202] based on the Debye-Scherrer formula [15] shown in Table 2.

\subsection{Magnetic Properties}

The magnetic properties of the hexagonal ferrite powders are recorded at room temperature on a vibrating sample magnetometer (VSM) (Lake Shore, Model 7404). Fig. 2(a) shows the field dependence of the magnetization curves for $\mathrm{BaCo}_{2-x} \mathrm{Ni}_{x} \mathrm{Fe}_{16} \mathrm{O}_{27}(x=0.4,0.8,1.2,1.6,2.0)$ samples measured at room temperature under an applied field of $12.5 \mathrm{KOe}$. Saturation Magnetization $(M s)$, Coercivity $(H c)$, retaintivity $(M r)$ and squareness ratio $(M r / M s)$ have been calculated from obtained hysteresis loops and listed in Table 2. The variation of $M s$, $M r$ and $M r / M s$ with nickel content $(x)$ is shown in Fig. 2(b). The saturation magnetization and remanence values are found higher in $x=0.8$ sample. The saturation magnetization and coercive field values were found 
TABLE 1. Lattice constant $a, c$, ratio $(c / a)$, volume of unit cell $(V)$ and crystallite size $\left(D_{x r d}\right)$ of $\mathrm{BaCo}_{2-x} \mathrm{Ni}_{x} \mathrm{Fe}_{16} \mathrm{O}_{27}$ hexaferrite samples

\begin{tabular}{cccccc}
\hline $\begin{array}{c}\text { Nickel } \\
\begin{array}{c}\text { Concentration } \\
(\boldsymbol{x})\end{array}\end{array}$ & $\begin{array}{c}\text { Lattice } \\
\text { Parameter } \\
\boldsymbol{a}[\AA]\end{array}$ & $\begin{array}{c}\text { Lattice } \\
\text { Parameter } \\
\boldsymbol{c}[\AA]\end{array}$ & $(\boldsymbol{c} / \boldsymbol{a})$ & $\begin{array}{c}\text { Cell Volume } \\
\boldsymbol{V}[\AA]^{\mathbf{3}}\end{array}$ & $\begin{array}{c}\text { Crystalline } \\
\text { size } \boldsymbol{D}_{\boldsymbol{x r d}} \\
{[\mathbf{n m}]}\end{array}$ \\
\hline 0.4 & 5.885 & 33.100 & 5.624 & 992.747 & $15.55 \pm 0.78$ \\
0.8 & 5.885 & 33.105 & 5.625 & 992.898 & $15.58 \pm 0.78$ \\
1.2 & 5.885 & 33.109 & 5.626 & 993.018 & $15.09 \pm 0.75$ \\
1.6 & 5.810 & 32.846 & 5.653 & 960.180 & $14.38 \pm 0.72$ \\
2.0 & 5.819 & 32.995 & 5.670 & 967.526 & $13.19 \pm 0.66$ \\
\hline
\end{tabular}

TABLE 2. Room temperature Magnetic parameters of $\mathrm{BaCo}_{2-x} \mathrm{Ni}_{x} \mathrm{Fe}_{16} \mathrm{O}_{27}$ samples prepared by a simple heat treatment method and calcined at $650{ }^{\circ} \mathrm{C}$ for 3 hours

\begin{tabular}{ccccc}
\hline $\begin{array}{c}\text { Ni concent } \\
(\boldsymbol{x})\end{array}$ & $\boldsymbol{M s}[\mathrm{emu} / \mathbf{g}]$ & $\boldsymbol{M r}[\mathrm{emu} / \mathbf{g}]$ & $\boldsymbol{H c}[\mathrm{KOe}]$ & $\boldsymbol{R}=(\boldsymbol{M r} / \mathbf{M s})$ \\
\hline 0.4 & 22.67 & 8.42 & 1.20 & 0.37 \\
0.8 & 37.77 & 18.00 & 1.00 & 0.47 \\
1.2 & 20.29 & 7.75 & 0.99 & 0.38 \\
1.6 & 27.04 & 12.25 & 0.85 & 0.45 \\
2.0 & 22.62 & 6.01 & 0.21 & 0.27 \\
\hline
\end{tabular}

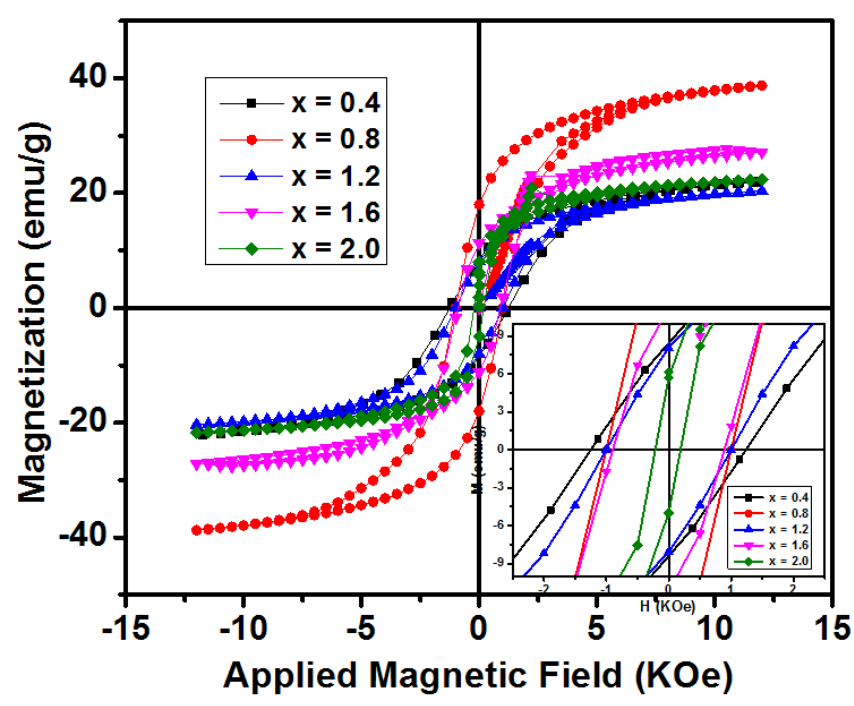

(a)

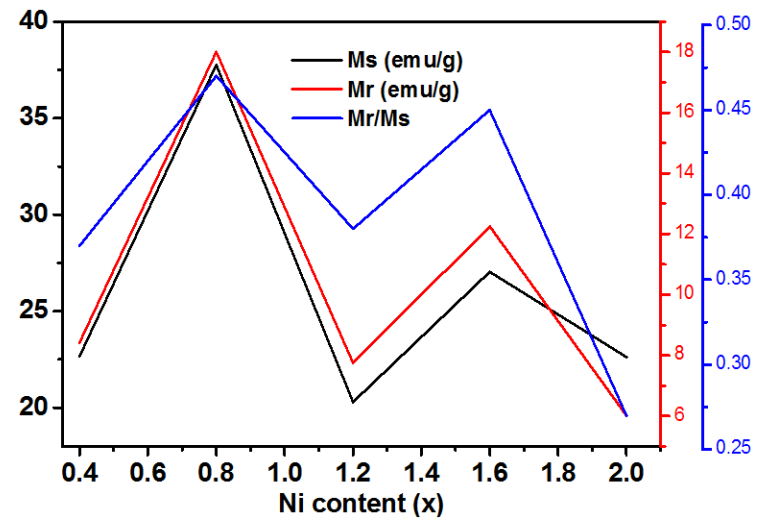

(b)

FIG. 2. (a) Field Dependent magnetic properties and (b) variation of Mr, Ms and Mr/Ms for of $\mathrm{BaCo}_{2-x} \mathrm{Ni}_{x} \mathrm{Fe}_{16} \mathrm{O}_{27}(x=0.4,0.8,1.2,1.6,2.0)$ hexaferrite samples, prepared using a simple heat treatment method and calcinated at $650{ }^{\circ} \mathrm{C}$ for 3 hours

to be low in prepared samples compared to other doped barium hexagonal ferrites $[8,16]$. The lower values of saturation magnetization and coercivity may be due to many reasons; surface effects, particle size and morphology, crystallographic defects, site occupancy of substituted ions in hexagonal lattice, phase impurity [17].

The ratio $R$ of the remanence to the saturation magnetization $(M r / M s)$ indicates the domain structure of prepared samples. A $M r / M s$ value of $\sim 0.5$ is indicative of single domain and the lower value is associated with a multidomain structure [18]. In the present case, samples $x=0.4,1.2,2.0$ show $R<0.5$, indicating the formation of a multidomain structure, while samples $x=0.8$ and 1.6 exhibited $R \cong 0.5$ confirming the formation of crystalline single domain structure. The hysteresis loops of $x=0.4$ to 1.8 samples possessed hard magnetic character while the $x=2.0$ sample showed soft ferrite behavior. 


\section{Conclusions}

Nickel-doped barium cobalt hexagonal ferrites- $\mathrm{BaCo}_{2-x} \mathrm{Ni}_{x} \mathrm{Fe}_{16} \mathrm{O}_{27}(x=0.4,0.8,1.2,1.6$ and 2.0) were synthesized using a simple heat treatment method. X-ray diffraction analysis confirmed the formation of mixed phases of M, W (both hexaganal) and S (spinel). There was little change in the values of the lattice constants- $a$ and $c$ with addition of nickel in prepared barium cobalt hexaferrite powder. $\mathrm{BaNi}_{2} \mathrm{Fe}_{16} \mathrm{O}_{27}$ hexaferrite exhibits soft ferrite nature, while other nickel substitutes barium cobalt ferrites show hard ferrite behavior.

\section{Acknowledgements}

One of the authors (Chetna C. Chauhan) acknowledge the funding support from Gujarat Council of Science and Technology (GUJCOST/MRP/2014-15/432, dated 30/06/2014) Gandhinagar. The work is also supported by DRS-SAP-Phase-I program of UGC (F.530/10/DRS/2010 (SAP-I)), New Delhi, India.

\section{References}

[1] Pullar R.C. Hexagonal Ferrites: A review of the synthesis, properties and applications of hexaferrite ceramics. Prog. Mater Sci., 2012, 57, P. 1191-1334.

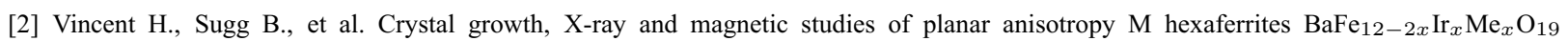
(Me=Zn, Co). J. Mag. Mag. Mat., 1991, 101 (1-3), P. 170-172.

[3] Mendoza-Suarez G., Rivas-Vazquez L.P., et al. Magnetic properties and microstructure of $\mathrm{BaFe}_{116-2 x} \mathrm{Ti}_{x} \mathrm{M}_{x} \mathrm{O}_{19}\left(\mathrm{M}=\mathrm{Co}, \mathrm{Zn}_{2}, \mathrm{Sn}\right)$ compounds. Physica B: Cond. Mat., 2003, 339 (2), P. 110-118.

[4] El-Saadawy M. Thermal conductivity and thermoelectric power of the $\mathrm{Zn}_{2-x} \mathrm{Co}_{x} \mathrm{BaFe}_{16} \mathrm{O}_{27}$ hexagonal ferrites system. Mater. Lett., 1999, 39, P. 149-152.

[5] Campbell P. Permanent Magnet Materials and Their Application. Cambridge University Press, Cambridge, 1994.

[6] Ong C.K., Fang H.C., Yang Z., Li Y. Magnetic relaxation in Zn-Sn-doped barium ferrite nanoparticles for recording. J. Mag. Mag. Mat., 2000, 213, P. 413-417.

[7] Wang L.X., Song J., et al. The microwave magnetic performance of $\mathrm{Sm}^{3+}$ doped $\mathrm{BaCo}_{2} \mathrm{Fe}_{16} \mathrm{O}_{27}$. J. Alloys Compd., 2009, 481, P. 863866.

[8] Huang K., Liu X., et al. Structural and magnetic properties of Ca-substituted barium W-type hexagonal hexaferrites. J. Mag. Mag. Mat., 2015, 379, P. 16-21.

[9] Pawar R.A., Desai S.S., et al. Ce ${ }^{3+}$ incorporated structural and magnetic properties of M type barium hexaferrites. J. Mag. Mag. Mat., 2015, 378, P. 59-63.

[10] Iqbal M.J., Khan R.A. Enhancement of electrical and dielectric properties of Cr doped BaZn $\mathrm{n}_{2}$ W-type hexaferrite for potential applications in high frequency devices. J. Alloys Compd., 2009, 478, P. 847-852.

[11] Jotania R.B., Chauhan C.C., Menon S.K., Kulkarni B.D. Synthesis and magnetic properties of barium?calcium hexaferrite particles prepared by sol-gel and microemulsion techniques. J. Mag. Mag. Mat., 2008, 320, P. 1095-1101.

[12] Chauhan C.C., Jotania R.B. Microstructual, Thermal and Magnetic proeprties of cobalt doped barium calcium hexaferrite prepared by a sol gle route. Int. J. Adv. Eng. Tech (IJAET), 2012, 3 (2), P. 135-139.

[13] Smith J., Wijn H.P.J. Ferrites. Philips, Technical Library, Eindhoven, 1959.

[14] Lotgering F.K., Vromans P.H.G. Chemical instability of metal deficient hexagonal ferrite with W structure. J. Am. Ceram. Soc., 1977, 40, P. 416-418.

[15] Mandal K., Mandal S.P., Agudo P., Pal M. A study of nanocrystalline (Mn?Zn) ferrite in SiO 2 matrix. Appl. Surf. Sci., 2002, 182, P. 386-389.

[16] Castro S., Gayoso M., et al. Structural and Magnetic properties of barium hexaferrite nanostructured materials prepared by the combustion method. J. Magn. Magn. Mater, 1996, 152, P. 61-69.

[17] Battle X., Obradors X., et al. Surface spin canting in $\mathrm{BaFe}_{12} \mathrm{O}_{19}$ fine particles. J. Magn. Magn. Mater., 1993 , 124, P. 228.

[18] Jiles J.C. Recent advances and future direction in magnetic materials. Acta Materiala, 2003,51 (19), P. 5907-5939. 